\title{
Using interactive technologies and distance learning in sustainable education
}

\author{
Anna Rybakova ${ }^{1}$, Aleksandra Shcheglova ${ }^{2}$, Denis Bogatov ${ }^{2}$, and Liudmila Alieva ${ }^{3}$ \\ ${ }^{1}$ Center for Additional Professional Education Moscow Institute of Physics and Technology, \\ Kerchenskaya str., 1A, bldg. 1, Moscow, Russian Federation \\ ${ }^{2}$ Russian State Social University, Wilhelm Pik str. 4 p. 1, 129226 Moscow, Russian Federation \\ ${ }^{3}$ Department of Russian history, Pskov State University, 2 Lenin Square, 180000 Pskov, Russian \\ Federation
}

\begin{abstract}
This paper focuses on the use of interactive technologies and distance learning in sustainable education. It discusses how remote learning technologies can positively influence students' learning and entry in sustainable education. The paper looks at the use of distance learning in higher education as a means to help students in the built environment and its use within the education system. It studies and expands the theoretical research on the benefits of distance learning, where the study is remote and there is no personal contact with staff or students, and examines the impact of distance learning on the student's learning experience. It also proposes and evaluates potential solutions to overcome the barriers to learning in the built environment and create successful virtual learning communities, recognising that such improvements must be reconciled with the primary benefits identified. The paper provides an overview of sustainable distance learning within higher education and discusses the differences between learning outside the structural environment of a profession, what it means for the student's learning experience and the potential to overcome barriers to distance learning. This is a very timely topic in the times of COVID-10 pandemic. Lockdowns of the economy and social life impacted all spheres of education with schools and universities closed for long periods of time and all teaching moved to online and distance mode. However, coronavirus pandemic also brought the digital surge in the system of education, including the sustainable education. All these innovations might stay after the pandemic and help the education to evolve and to embrace more novel trends and technologies.
\end{abstract}

\section{Introduction}

Since distance learning is continuing to expand, educators must be careful to examine the problems caused by this paradigm shift. Distance learning is becoming a common practice, as evidenced by the number of universities offering distance learning programmes, companies offering distance learning programmes and the number of distance learning courses - K-12 learning projects that have already been set up or are currently in use $[1,2]$.

\footnotetext{
${ }^{*}$ Corresponding author: anya_rybakova@list.ru
} 
It was also noted that more and more students do not want and need traditional and flexible working hours. Thus, remote study became an ever more popular method, in order to obtain higher education which becomes clear by the number of the correspondence courses, which are offered at the university [3]. Distance learning has the potential to reach many more people through the use of online courses and other forms of learning such as social media and online learning. In literature, the term "distance learning" is used both for online-based programs and for programs that also include personal contacts. One has to distinguish the distance learning from a situation when courses are held at remote universities with local staff and students and staff never meet in person. Distance learning benefits students when and where they can devote themselves to learning, and it benefits all students, regardless of when, where or how they do it [4]. Information and communication technologies (ICT) can create distance learning institutions - learning platforms that enable many students who are far from the centre of learning to form themselves. Distance learning can support their families and be given the opportunity to work while raising their family or working full-time. In addition, the use of e-learning systems can offer a number of other benefits, such as helping to teach students in low-income and countries with limited access to educational resources, and providing students from other countries with the opportunity to learn globally and access higher education.

There are a number of other benefits of distance learning technologies, such as helping higher education institutions to combat the high cost of education and lack of access to resources for students in low-income countries. Institutions use distance learning technologies and often expect student outcomes to soar. Only by combining the right distance learning technologies with trained teachers and the focus on sustainable education, the educational institutions can offer more personalised teaching to positively impact students' learning outcomes in higher education $[5,6]$.

Distance learning technologies can also help rural and remote schools and universities to overcome the disadvantages of geographical isolation by expanding course offerings and learning opportunities, and connecting teachers and students with a broader range of resources and materials. Given the high cost of new technologies, more rural districts may be able to take advantage of distance learning [7]. Surveys of rural school districts show strong support for distance learning as a way to address teacher shortages and meet the needs of their students. Half of those surveyed supported distance learning as an alternative to traditional teaching and learning methods, and half favoured the use of online courses [8].

Universities and schools need to enhance their competences in distance learning. In doing so they might learn from each other. For example, the University of North Dakota offers a 34-hour virtual education program that focuses on the use of technology in education, communication and social media in the workplace. The curriculum combines training in psychology and communication and prepares graduates to use the latest technologies for educational purposes. It includes the leading curriculum for learning in virtual education (LCLE) and the university's first ever virtual learning course, Virtual Learning. The $100 \%$ online format can be completed in just two years and allows for a flexible schedule for professionals [9]. This can be a challenge for some lecturers and they may need to be trained professionally. It is believed that doctoral students will prefer online courses due to their better access to online resources and more flexible schedules. It is believed that distance learning at a higher education institution can be an important part of a student's development as an ICT specialist. If pupils' ICT skills can be improved and if pupils' attitudes towards online learning are positively influenced, distance learning in higher education could be used as a tool to increase the number of pupils who could have taken part and the quality of education. 


\section{Effective learning environments for sustainable education}

Teaching and learning methods tend to humanize and represent a new form of educational quality that suggests that they could potentially stimulate adequate action for the environment and sustainability, both at individual and collective levels. Projects of change appear to have been an important step in the development of a quality education that is more responsive to the needs of students and the environment, as well as to their own needs. During the implementation of the change projects, the participants show a strong interest in learning contexts by using and promoting teaching and learning methods that emphasize critical, cooperative and experiential values $[10,11]$.

However, the need to rethink education at all levels, including teacher training, cannot be separated from the current debate on the quality of education. Drawing on the results of a regional research programme involving ten countries in Southern Africa, the researchers argue that quality education not only focuses on learning for a sustainable future, but also on the processes that create learning links, such as learning in connection with social, cultural and economic development, as such processes tend to deepen understanding of context, concepts and practices, while improving inclusiveness and knowledge-based access [12]. All of these seem to offer a unique opportunity for learners to develop a deeper understanding and appreciation of the social and cultural context of their learning environment, both inside and outside the classroom.

It is therefore crucial that the knowledge, attitudes and behaviour of teachers are supported in the design of teaching and collaboration in the classroom. Over the past two decades, tech companies invested a lot of time, effort, and money in research into effective teaching and learning methods, and has decided that one of the best investments, governments can make to improve student learning is in teacher professional development [13]. Unless there is a strong focus on teacher training as a key component of a sustainable education system, this will only lead to disappointing results. There is a guidance design paradigm known as ADDIE, an acronym that stands for analysis, design, development, implementation and evaluation. It is the basis for designing effective learning environments for sustainable education systems. It notes that this paradigm, while generally accepted, does not take into account the importance of design for sustainability [14].

Generally. there are some key concepts that enable students to discuss together their importance for the design of innovative and sustainable educational approaches. It intends to guide its students in taking into account the learning environments used to teach students from underdeveloped regions of the world such as Africa, Asia, Latin America and the Middle East. Learning through design - based education and thus embedding the principles of self-determination - regulated learning, sustainable learning and sustainable teaching and learning practices. With regard to the above, some researchers note that even if a learning environment is designed to promote self-regulated learning [15]. Students can perceive the environment in two different ways. On the one hand, they might find this environment motivating and stimulating, on the other hand, threatening [16]. These phases should be coordinated when designing learning environments for sustainable learning and sustainable teaching and learning practices.

Lecturers can encourage students to consider their campus, whether it is in the city or in the countryside, as a classroom for sustainability. This can help students to understand and discuss sustainability issues and initiatives in the community and to present them to faculty and staff. Using an ecological footprint calculator is a useful tool for educators who want to engage students in wide-ranging topics [17]. Higher education offers a wide range of learning services to teachers who are considering including policies, research and community engagement in their courses. Raising awareness of the impact of environmental issues on students, faculty and staff is crucial to bring about positive change. Education must be a big 
part of the solution, and we should be grateful to schools and other educational organizations that are pioneering and inspiring others to do the same. It offers the opportunity to involve young people in complex sustainability issues and help to build a bridge between science and the humanities. Efforts are also being made to integrate curricula in these areas with projectbased learning opportunities, while ensuring a high degree of sustainability in the curriculum, such as the use of renewable energy and education for sustainability. There are also some educational institutions that are recognized as the ones that save energy, reduce costs, provide environmentally sustainable learning environments, protect health, and provide environmental education to promote academic achievement and community engagement. This approach protects health by reducing the chemical environmental hazards that negatively affect children's growth and development [18]. Students, teachers and school staff are trained in student-led green teams to create a healthier school. A better learning environment promotes health and education for all by reducing the risk of environmental chemicals and hazards that negatively affect childhood and young adulthood growth and development.

\section{Interactive educational process}

In the long run, educators, school districts, and states can use the information technologies worldwide to support continuous learning improvement and innovation. Families can be more confident about how they and their child learn throughout the school day. The method of "thinking, mating and sharing" is a great way for teachers to hear from students, even those who are quiet in class. When students feel comfortable in a class to exchange ideas, they can learn through collaboration and engagement. Students are more involved in class discussion and participation and make cumulative assessments of their progress. Properly implemented, this saves teachers time, helps students get involved, keeps students prepared for class, and keeps teachers informed throughout the learning process [19].

Teachers and trainers can also be supported by observing students and seeing if they understand the material under discussion. By creating these conditions, the activities of the teacher can be replaced by activities for the students aimed at developing the ability to communicate effectively, analyse alternative opinions, and to build intellectual viability, confidence and ability, which also constitutes the ability to make informed decisions. The role of teachers is also changing, as they do not provide ready-made answers to the questions discussed, as in traditional teaching, but rather encourage students to seek solutions independently and in an informed manner [20].

It is generally accepted that knowledge can be acquired by listening to lectures and reading texts, as well as other forms of learning such as reading, writing and writing. In some cases, it is even the information that is transferred from one form of learning process to another, such as from a lecture to a book, or even from the classroom to the office. In summary, teaching and targeted guidance in the learning process are complex and can take many forms. One of the goals is to create comfortable learning conditions in which students feel comfortable themselves, which makes the learning process productive [21]. Consider measures of students' desired learning, including overlapping goals that are taught as tested goals, and control of student behaviour and classroom activities. Under the best conditions, it takes many years of experience for most teachers to fulfil the ideal teaching practices that they have set themselves as protections for undergraduate students, but it is critical that classroom activities are taken into account. Interactive learning is an organization of the educational process, whose essence is the interaction of students, teachers and other students in the classroom in many ways. Interactive activities and lessons include the organisation, development, dialogue and communication that lead to the development of students' knowledge, understanding and understanding and the learning process [22]. Interactive 
learning takes into account the needs of the students, the students analyse their own activities, their personal experiences are included, targeted adjustments of knowledge are made and optimal results are achieved. Interactive learning expands the educational offer, helps to establish emotional contact with the students, teaches teamwork, takes into account the needs of each student, expands and expands, expands and expands. Educational institutions worldwide use active and interactive forms of study to develop the professional skills of students.

\section{Using interactive technologies for multidisciplinary sustainable education}

Multidisciplinary university usually involve a wide range of sub-fields, including digital media, streaming media and social media. Through education, digital technologies affect our lives and our societies. There is a number of interesting aspects, some of which are interesting for both practising managers and scientists [23]. Today's students and pupils must be entrepreneurs who monitor market trends, exploit innovation, create intellectual property, and apply aesthetic solutions to enhance the value of products, services, and experiences. The design, development and evaluation of technologies should be carried out in a participatory design process involving teachers and students. A rigorous scientific approach should not exclude the possibility of being inspired by the humanities, and especially the arts. Start has developed a growing awareness of how art and science are strongly interlinked when it comes to the design process and the development of innovative products and services. In the case of multisensory technologies in education, we believe that the exceptional ability of the arts to communicate content through sound, music and visual media represents a significant added value to the educational perspective. This is an opportunity to design and develop technologies based on sound scientific knowledge and tailored to the real needs of teachers and students. We believe that this becomes a key element in effectively supporting an embodied, enactive educational approach that uses the best sensory modalities to teach concepts in schools. We already know that a multidisciplinary approach is needed to understand how these technologies work, what benefits they can have, how people interact while working on the project, and what is learned. Based on our experience with technologically advanced learning projects, we suggest that we consider it important to "fully seize" this opportunity before taking advantage of it [24].

On the other hand, there is little research on the benefits of working on interdisciplinary technology-enhanced learning (TEL) research. Scanlon et al. reported on an analysis of prototype TEL projects funded by the National Science Foundation and the Office of Science and Technology Policy at the U.S. Department of Energy [25, 26].

Other fields of interest demonstrated the creation of knowledge, but there was relatively little in comparison to the interest in studying it. On the one hand, there are many examples of projects that work in teams, such as in the fields of computer science and technology, but also in other areas of science and in human-computer interaction. In general, their research objectives are to promote multidisciplinary scientific research and interdisciplinary cooperation in the field of computer science and technology. These goals require the collection of recognized scientific credibility and cutting-edge expertise in a wide range of disciplines, including engineering, mathematics, physics, chemistry, biology and physics. There is a need to use the resources available to maintain interdisciplinary cooperation in order to advance research and development of TEL technologies. Although some aspects such as data collection have improved, the results of some studies suggest that the use of ICT itself is not sufficient to change team dynamics and improve the delivery of knowledge and the quality of education. There are also human and organizational factors that support the successful use of technology in education process $[27,28]$. Specialists who understand how 
to use and interpret technology and information systems, experts who design clinical databases for teams, design interactive systems and analyse clinical records during meetings are of particular importance. ICT alone is a tool that can be used to improve the learning process, but there is also a need for human organisational factors to support the successful use of these technologies in health care. They have a range of tools to capture and describe user needs and design interactive systems, including conceptual structural design. They also have an access to ethnographic and other qualitative research, which seeks to understand the needs and practices of people in the use and potential use of interactive technologies and in their use. In fact, identifying these requirements and developing designs is an active research topic that calls for the use of existing and novel techniques.

The use of ICT tools would allow children and young adults to have the same teaching methods thus naturally breaking down barriers between peers and facilitating social interaction. We believe that they are essential to effectively support educational approaches that use the best techniques that are appropriate for communicating concepts. They allow for the development of different strategies that teachers can choose more flexibly. Some newer technology can be designed to introduce children to the geometric concepts and forms as well as to explain them complex concepts such as global warming, climate change, or sustainable development.

\section{Conclusions}

The results of this paper can lead to the development of a new way of structuring learning so that students can learn more effectively and efficiently than ever before. In this respect, vocational school teachers and university lecturers alike face the challenge of developing and implementing teaching methods aimed at activating the interests and abilities of pupils and their learning ability.

One of the ways to organise the educational process is to use interactive learning methods such as seminars and training elements for better explaining concepts such as sustainable growth or global environmental changes. Professors and teachers are considering the possibility of designing an active and interactive form of work for students, as well as introducing seminar and training elements into practical teaching, which is an innovative approach to educational processes.

All in all, the novel technologies could and should be used in distance learning and education in general and for sustainable education in particular. Recent COVID-19 pandemic that helped to digitalize the education at all levels became a powerful trigger that would help to accomplish the transition to digital and online education that has the benefits of all powerful tools, like augmented reality or virtual reality, for explaining and visualizing the complex issues. Sustainable education in schools and universities would only benefit from this transition.

\section{References}

1. K. Lee, H. Choi, Y. Cho, The Internet and Higher Education, 41, 25-33 (2019)

2. U. Kaden, Education Sciences, 10(6), 165 (2020)

3. Z. Gardanova, V. Ponkratov, N. Kuznetsov, N. Nikitina, O. Dudnik, E. Latypova, S. Shcherbatykh, Journal of Open Innovation: Technology, Market, and Complexity, 6(4), 1-21 (2020)

4. L. Dos Santos, International Journal of Education and Practice, 8(1), 134-148 (2020)

5. N. Colvard, C. Watson, H. Park, International Journal of Teaching and Learning in Higher Education, 30(2), 262-276 (2018) 
6. E. Agormedah, E. Henaku, D. Ayite, E. Ansah, Journal of Educational Technology and Online Learning, 3(3), 183-210 (2020)

7. D. Zinger, J. Sandholtz, C. Ringstaff, The Rural Educator, 41(2), 14-30 (2020)

8. A. Picciano, J. Seaman, I. Allen, Journal of Asynchronous Learning Networks, 14(4), 17-35 (2010)

9. R. Ferdig, E. Baumgartner, R. Hartshorne, R. Kaplan-Rakowski, C. Mouza (eds), teaching, technology, and teacher education during the COVID-19 pandemic: stories from the field (2020)

10. P. Payne, Journal of Environmental Education, 51(2), 113-143 (2020)

11. W. Penuel, R. Riedy, M. Barber, D. Peurach, W. LeBouef, T. Clark, Review of Educational Research, 90(5), 627-674 (2020)

12. H. Lotz-Sisitka, E. Rosenberg, P. Ramsarup, Environmental Education Research, 1-29 (2020)

13. M. Goralski, T. Tan, The International Journal of Management Education, 18(1), 100330 (2020)

14. C. Budoya, M. Kissaka, J. Mtebe, International Journal of Education and Development using ICT, 15(1), 1-20 (2019)

15. J. Broadbent, M. Fuller-Tyszkiewicz, Educational technology research and development, 66(6), 1435-1455 (2018)

16. G. Goloshumova, O. Ershova, V. Salakhova, A. Kidinov, S. Nalichaeva, V. Yanysheva, Eurasian Journal of Biosciences, 13(2), 1867-1874 (2019)

17. W. Villegas-Ch, X. Palacios-Pacheco, S. Luján-Mora, Sustainability, 11(10), 2857 (2019)

18. N. Anwar, N. Mahmood, M. Yusliza, T. Ramayah, J. Faezah, W. Khalid, Journal of Cleaner Production, 256, 120401 (2020)

19. E. Tokareva, Y. Smirnova, L. Orchakova, Education and Information Technologies, 24(5), 3219-3234 (2019)

20. Y. Waghid, N. Davids, Teachers Matter: Educational Philosophy and Authentic Learning (2020)

21. C. Rapanta, L. Botturi, P. Goodyear, L. Guàrdia, M. Koole, Postdigital Science and Education, 2(3), 923-945 (2020)

22. I. Backfisch, A. Lachner, K. Stürmer, K. Scheiter, Computers \& Education, 104159 (2021)

23. A. Lytos, T. Lagkas, P. Sarigiannidis, K. Bontcheva, Information Processing \& Management, 56(6), 102055 (2019)

24. S. Seufert, J. Guggemos, M. Sailer, Computers in Human Behavior, 115, 106552 (2021)

25. L. Daniela, A. Visvizi, C. Gutiérrez-Braojos, M. Lytras, Sustainability, 10(11), 3883 (2018)

26. E. Scanlon, S. Anastopoulou, G. Conole, A. Twiner, Frontiers in Education, 4, 134 (2019)

27. S. Kim, M. Raza, E. Seidman, Research in Comparative and International Education, 14(1), 99-117 (2019)

28. R. Malik, Journal of Sustainable Development Education and Research, 2(1), 9-20 (2018) 